\title{
HUBUNGAN KESIAPAN TEKNOLOGI INFORMASI DAN KOMUNIKASI (TIK) DENGAN MOTIVASI BELAJAR KIMIA SISWA
}

\author{
Megawati $^{1 *}$, Yayuk Andayani ${ }^{2}$, Eka Junaidi ${ }^{3}$ \\ 1,2,3 Program Studi Pendidikan Kimia FKIP Universitas Mataram \\ *Coressponding Author, Email: megawatinim046@gmail.com
}

Received: 21 Oktober 2019

Accepted: 30 November 2019

Publish: 30 November 2019

doi: 10.29303/cep.v2i2.1414

\begin{abstract}
Abstrak
Penelitian ini bertujuan untuk mengetahui ada atau tidak ada hubungan antara kesiapan teknologi informasi dan komunikasi (TIK) dengan motivasi belajar kimia siswa kelas XI IPA SMA Negeri di Mataran tahun ajaran 2019/2020. Jenis penelitian ini adalah penelitian kuantitatif ex-post facto. Populasi dalam penelitian ini meliputi seluruh siswa kelas XI IPA SMA Negeri 4 Mataram dan SMA Negeri 7 Mataram yang berjumlah 333 siswa. Teknik yang digunakan untuk pengambilan sampel yaitu dengan menggunakan teknik stratified proportional random sampling. Sampel pada penelitian ini sebanyak 178 siswa atau sebesar $53,453 \%$ dari populasi. Pengumpulan data kesiapan teknologi informasi dan komunikasi (TIK) dan motivasi belajar kimia siswa menggunakan angket. Uji validitas instrumen dilaksanakan pada 46 responden. Uji validitas instrumen menggunakan korelasi product moment Pearson. Hasil uji validitas instrumen angket kesiapan TIK dan angket motivasi belajar kimia siswa masing-masing 25 item yang valid dari 35 item. Uji reliabelitas menggunakan rumus alpha Cronbach's. Hasil uji reliabelitas untuk kedua angket dikategorikan sangat tinggi. Data kesiapan TIK dan motivasi belajar kimia dalam penelitian ini terdistribusi normal dan memiliki hubungan yang linear. Nilai korelasi antara kesiapan TIK dengan motivasi belajar kimia sebesar 0,41 dengan kategori sedang. Konstribusi kesiapan TIK terhadap motivasi belajar kimia sebesar $16,81 \%$.
\end{abstract}

Kata Kunci: Kesiapan teknologi informasi dan komunikasi, motivasi belajar kimia.

\section{THE CORRELATION BETWEEN READINESS OF INFORMATION AND COMMUNICATION TECHNOLOGY WITH MOTIVATION ON CHEMISTRY LEARNING OF STUDENTS}

\begin{abstract}
This study aimed to determine whether or not the correlation of readiness information communication of technology with motivation on chemistry learning of students class XI IPA SMA Negeri Mataram academic year of 2019/2020. This reseach types is quantitative ex-post facto. Population in this study covers the whole of students class XI IPA SMA State 4 Mataram and SMA State 7 Mataram which number 333 students. The technique used for sampling by using proporsioonal random sampling technique. Sample in this study were 178 students or $53.453 \%$ of population. Data collection was used questionnaire readiness information communication of technology and motivation student's on chemistry learning. Test try instrument held on 46. Instrument validity test was used Product Moment Correlation. Result of validity test questionnare readiness ICT and motivation obtained 25 from 35 items. The reliability test was used Alpha Cronbach's formula. The reliability test results for both questionnaires are categorized as high. The results of the data questionnaire were expressed in the form of a correlation. The reliability test results for both questionnaires are categorized very high. Data on ICT readiness and chemistry learning motivation in this study are normally distributed and have a linear relationship. The correlation value between ICT readiness and
\end{abstract}


chemistry learning motivation is 0.41 with the correlation category being medium. The contribution of ICT readiness to chemistry learning motivation is $16.81 \%$.

Keywords: Readiness of information and communication technology, chemistry learning motivation.

\section{PENDAHULUAN}

Kimia merupakan salah satu mata pelajaran wajib di SMA khususnya program studi IPA. Salah satu tujuan mata pelajaran kimia yaitu membentuk sikap positif terhadap ilmu kimia dengan menyadari keteraturan dan keindahan alam serta mengagungkan kebesaran Tuhan yang Maha Esa (Hasibuan dan Ratih, 2018; Fitriani, dkk., 2019). Namun sikap positif siswa terhadap ilmu kimia belum optimal jika ilmu kimia dianggap sebagai mata pelajaran sulit. Oleh karena itu ilmu kimia dijadikan alat untuk menimbulkan rasa tertarik siswa dalam belajar dengan cara menyediakan fasilitas belajar kimia yang menarik dan terkini agar memudahkan siswa dalam memperoleh informasi tentang kimia sehingga terbentuk sikap positif siswa terhadap ilmu kimia (Musbhirah, dkk., 2018).

Menurut Setiawan (2017) belajar dipengaruhi oleh dua faktor yaitu internal dan eksternal. Faktor internal berupa psikologis pelajar yang meliputi intelegensi, perhatian, minat, bakat, motivasi, kematangan dan kesiapan. Sedangkan faktor eksternal meliputi keluarga, sekolah dan masyarakat.

Sekolah merupakan salah satu faktor eksternal belajar, peran sekolah dalam pembelajaran adalah menyediakan infrastruktur pembelajaran. Fasilitas atau Infrastruktur pembelajaran yang berkembang sangat pesat adalah teknologi informasi dan komunikasi (TIK). Seiring berkembangnya teknologi informasi dan komunikasi sumber belajar juga ikut mengimbangi kemajuan tersebut salah satunya adalah sumber belajar kimia. Fasilitas belajar berbasis teknologi informasi dan komunikasi (TIK) yang digunakan dalam proses pembelajaran kimia berupa komputer, internet, website serta proyektor.

Beberapa sekolah negeri tingkat SMA di Mataram telah terakreditasi A dengan nilai kesiapan sarana dan prasarana diatas 90 , sekolah tersebut menyediakan laboratorium komputer serta koneksi internet yang cukup memadai sehingga pembelajaran kimia yang tidak dapat direalisasikan di laboratorium kimia serta materi yang masih dianggap sulit dapat diatasi dengan memanfaatkan teknologi informasi dan komunikasi seperti komputer, koneksi internet, website dan proyektor LCD. Di era globalisasi saat ini, penjelasan materi dan percobaanpercobaan kimia yang menarik banyak disediakan di internet sehingga dengan kesiapan TIK di sekolah memudahkan siswa untuk memperoleh informasi yang menarik tentang ilmu kimia dan diprediksi akan meningkatkan motivasi belajar kimia siswa.

Berkenaan dengan penggunaan teknologi informasi dan komunikasi, guru dan siswa sebagian besar menggunakan teknologi informasi dan komunikasi untuk mengunggah dan mengunduh materi pelajaran (Mazana, 2019). Adapun penelitian pemanfaatan teknologi informasi dan komunikasi dalam pembelajaran kimia yang dilakukan oleh Putra (2017) mengatakan pembelajaran berbasis ICT (Information and Communication Technology) dapat meningkatkan motivasi belajar kimia siswa. Hal ini didukung oleh penelitian yang dilakukan oleh Agrahari dan Singh (2013) mengatakan bahwa pembelajaran kimia dengan memanfaatkan teknologi informasi dapat memotivasi siswa dalam belajar.

Berangkat dari hal tersebut peneliti tertarik untuk melakukan penelitian yang berjudul "Hubungan Kesiapan Teknologi Informasi dan Komunikasi (TIK) dengan Motivasi Belajar Kimia Siswa Kelas XI IPA SMA Negeri di Mataram Tahun Ajaran 2019/2020”.

\section{METODE PENELITIAN}

Penelitian ini dilakukan dengan tiga tahap yaitu tahap pertama melakukan perencanaan pada bulan Desember 2018, tahap kedua merupakan tahap persiapan dan pelaksanaan pada bulan Juli 2019, tahap ketiga merupakan tahap analisis data dan penulisan laporan dalam rangka menyusun tugas akhir atau skripsi pada bulan Juli 2019 hingga selesai. Penelitian ini dilaksanakan di dua sekolah yaitu SMAN 4 Mataram dan SMAN 7 Mataram.

Jenis penelitian yang digunakan pada penelitian ini adalah penelitian deskriptif kuantitatif, dimana data penelitian yang 


\section{Chemistry Education Practice, 2 (2), 2019 - 52}

Megawati, Andayani, Junaidi

digunakan berupa angka-angka dan diolah menggunakan statistik (Sugiyono, 2017). Adapun metode penelitian yang digunakan yaitu metode expost facto. Menurut Syaodih (2010) dalam Hamdi (2014) metode expost facto merupakan penelitian yang meneliti hubungan sebab-akibat yang tidak dimanipulasi atau diberi perlakuan (dirancang dan dilaksanakan).

Variabel penelitian yang digunakan pada penelitian ini yaitu variabel atribut dan variabel terikat. Kesiapan TIK sebagai variabel atribut dan motivasi belajar kimia siswa sebagai variabel terikat. Penentuan populasi pada penelitian ini didasarkan pada kualitas kesiapan sarana dan prasarana SMA Negeri di Mataram yang memiliki nilai diatas 90 dimana nilai kesiapan diatas 95 diwakili oleh SMAN 7 Mataram sementara nilai kesiapan dibawah 95 diwakili oleh SMAN 4 Mataram. Populasi dalam penelitian ini adalah seluruh siswa kelas XI MIA di SMAN 4 Mataram dan SMAN 7 Mataram yang berjumlah 333 siswa.

Teknik pengambilan sampel (sampling) yang digunakan pada penelitian ini yaitu teknik stratified proportionate random sampling, untuk menentukan sampel pada penelitian ini digunakan rumus Isaac dan Michael (Sugiyono, 2017) sehingga diperoleh 178 sampel atau $53,453 \%$ dari populasi.

Instrumen penelitian yang digunakan pada penelitian ini yaitu lembar angket atau questionnaire yang terdiri dari angket kesiapan teknologi informasi dan komunikasi (TIK) dan angket motivasi belajar kimia siswa. Menurut Arikunto dalam Sari (2018) instrumen penelitian adalah alat atau fasilitas yang digunakan oleh peneliti dalam mengumpulkan data agar pekerjaannnya lebih mudah dan hasilnya lebih baik.

Angket dalam penelitian ini merupakan angket tertutup dengan menggunakan skala Likert. Menurut Sugiyono, skala Likert merupakan skala yang digunakan untuk mengukur sikap, pendapat dan persepsi seseorang tentang suatu gejala atau fenomena tertentu (Oktavia, 2015).

Uji validitas yang digunakan pada penelitian ini adalah uji validitas ahli dan validitas empiris. Angket kesiapan TIK divalidasi oleh ahli di bidang TIK, sementara angket motivasi belajar kimia siswa divalidasi oleh ahli di bidang psikolog pendidikan.

Validitas empiris dihitung menggunakan korelasi product moment Pearson. Uji reliabilitas instrumen menggunakan rumus alfa
Cronbach, Uji prasyarat menggunakan uji normalitas dan linearitas sementara uji hipotesis menggunakan analisis regresi sederhana dan korelasi product moment Pearson (Sugiyono, 2017).

\section{HASIL DAN PEMBAHASAN}

Data penelitian ini diperoleh dari 178 sampel dari 333 populasi yang berasal dari siswa kelas XI MIA SMAN 4 Mataram dan SMAN 7 Mataram. Data yang dikumpulkan meliputi data angket kesiapan teknologi informasi dan komunikasi (TIK) dan angket motivasi belajar kimia siswa.

Hasil perhitungan validitas dari angket kesiapan TIK dan angket motivasi belajar kimia diperoleh masing-masing 25 item valid dari 35 item pernyataan. Hasil uji coba instrumen untuk angket kesiapan teknologi informasi dan komunikasi (TIK) diperoleh nilai rhitung sebesar 0,9055 dan angket motivasi belajar kimia diperoleh nilai rhitung sebesar 0,9145 dengan tingkat reliabelitas sangat tinggi.

Chi-Kuadra hitung kesiapan TIK = 12,384. Chi-Kuadrat hitung motivasi belajar kimia $=7,143$. Sementara Chi-Kuadrat tabel $=$ 15,50. Berdasarkan data tersebut diperoleh nilai Chi-Kuadrat hitung data kesiapan TIK dan motivasi belajar kimia lebih kecil dari ChiKuadrat tabel maka data dikatakan terdistribusi normal.

Hasil yang diperoleh dari uji linearitas pada taraf signifikan 5\% menunjukkan nilai koefisien Fhitung $=1,23$ lebih kecil dari nilai koefisie Ftabel $=1,49$ sehingga dapat dikatakan bahwa kesiapan TIK dengan motivasi belajar kimia memiliki hubungan yang linear.

Hasil perhitungan regresi sederhana pada taraf signifikan $5 \%$ dengan ( $\mathrm{dk}$ pembilang $=1$ dan $\mathrm{dk}$ penyebut $=\mathrm{n}-2=178-2=176)$ diperoleh Fhitung $=34,7$ lebih besar dari Ftabel $=3,91$ sehingga koefisien arah regresi (b) itu memiliki arti (koefisien b tidak sama dengan nol) dengan persamaan regresi sederhana sebagai berikut:

$$
\mathrm{Y}=0,3269 \mathrm{X}+47,981
$$

Hasil uji hipotesis koefisien korelasi antara kesiapan TIK dengan motivasi belajar kimia menggunakan rumus korelasi product moment Pearson diperoleh rhitung $=0,41$. Kemudian pada $\mathrm{n}=178$ dan taraf signifikan $5 \%$ diperoleh rtabel $=0,148$, karena rhitung lebih besar dari rtabel maka dapat disimpulkan bahwa Ha diterima atau penolakan terhadap Ho, artinya 
bahwa terdapat hubungan yang positif dan signifikan antara kesiapan TIK dengan motivasi belajar kimia siswa. Adapun skor rata-rata kesiapan TIK dan motivasi belajar kimia siswa disajikan pada Grafik 3.1

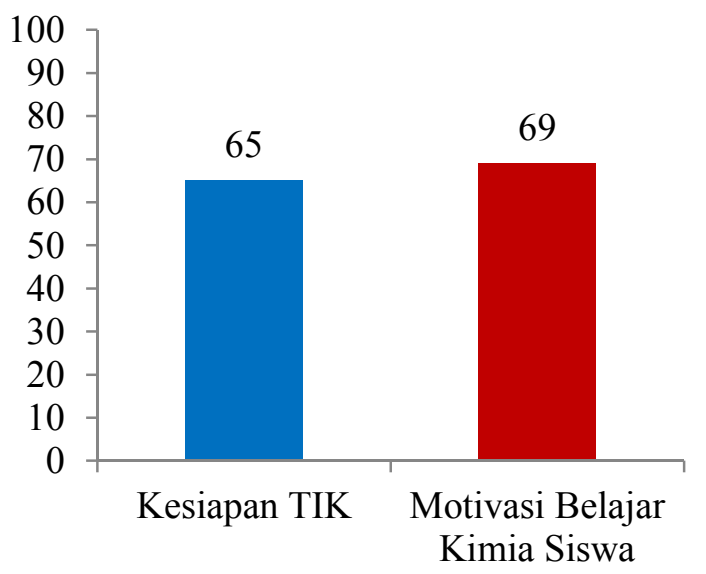

\section{Gambar 1. Skor Rata-Rata Kesiapan TIK dan Motivasi Belajar Kimia Siswa}

Skor rata-rata kesiapan TIK dari grafik tersebut sebesar 65 sementara motivasi belajar kimia siswa sebesar 69. Berdasarkan kriteria kesiapan TIK dan motivasi belajar kimia yang dimodifikasi dari Muktar (2015) maka skor tersebut berada pada interval $55 \leq \mathrm{x} \leq 69$ atau kesiapan TIK dan motivasi belajar kimia siswa berada pada kategori sedang, dari grafik tersebut diketahui bahwa ada hubungan antara kesiapan TIK dengan motivasi belajar kimia siswa dimana ketika kesiapan TIK berada pada kategori sedang motivasi belajar kimia siswa juga berada pada kategori sedang.

Skor rata-rata kesiapan TIK dan motivasi belajar kimia siswa tiap indikator memiliki interval skor yang berbeda-beda sehingga untuk memberikan kategori tiap indikator juga berbeda-beda, hal ini dikarenakan setiap indikator pada angket memiliki jumlah item yang berbeda-beda. Kesiapan TIK tip indikator disajikan pada Grafik 3.2

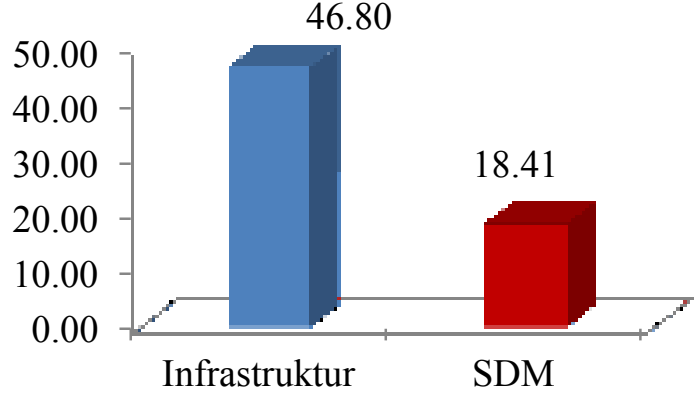

\section{Gambar 2. Kesiapan TIK Tiap Indikator}

Kesiapan TIK dalam penelitian ini ditinjau dari kesiapan infrastruktur dan sumber daya manusia (SDM). Kesiapan infrastruktur dan SDM dikategorikan sedang. Adapun motivasi belajar kimia siswa tiap indikator disajikan pada Grafik 3.3

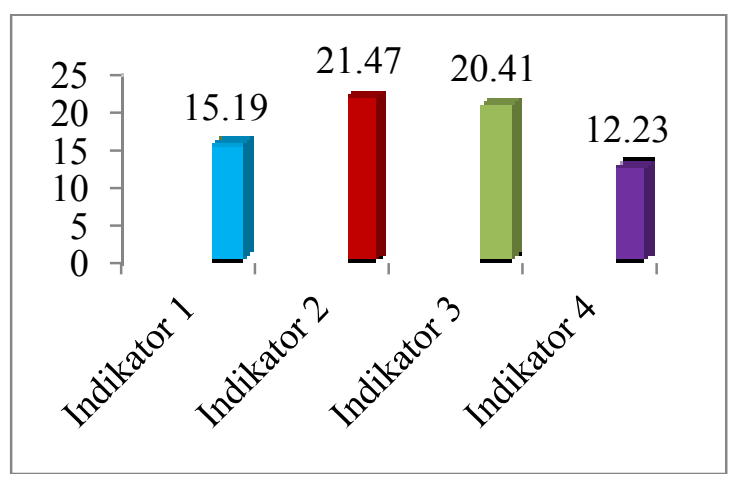

Gambar 3. Motivasi Belajar Kimia Siswa Tiap Indikator

\section{Keterangan:}

Indikator 1: Berprestasi dalam belajar kimia Indikator 2: Ketekunan dalam belajar kimia Indikator 3 : Kemandirian dalam belajar kimia Indikator 4 : Keuletan menghadapi kesulitan belajar kimia

Motivasi belajar kimia siswa ditinjau dari aspek pengetahuan, sikap dan keterampilan yang terdiri dari empat indikator, dimana indikator berprestasi dalam belajar kimia dan kemandirian dalam belajar kimia dikategorikan sedang. Sementara indikator ketekunan dalam belajar kimia dan keuletan menghadapi kesulitan belajar kimia dikategorikan tinggi.

Kesiapan TIK dengan kategori sedang berbanding lurus dengan motivasi berprestasi siswa dan kemandirian siswa dalam belajar kimia yang juga berada pada kategori sedang, tetapi ketekunan siswa dalam belajar kimia berada pada kategori tinggi, hal ini dikarenakan siswa hanya mengikuti proses pembelajaran kimia serta memiliki rasa ingin tahu yang tinggi 


\section{Chemistry Education Practice, 2 (2), 2019 - 54}

Megawati, Andayani, Junaidi

tetapi keingintahuan siswa tidak didukung oleh fasilitas di sekolah sehingga berdampak pada prestasi akademik dan kemandirian belajar siswa.

UNESCO (United Nation Education, Scientific, and Cultural Organization) merekomendasikan empat pilar dalam bidang pendidikan salah satunya adalah learning to know. Proses pembelajaran ini memungkinkan peserta didik mampu mengetahui, memahami dan menerapkan, serta mencari informasi dan menemukan pengetahuan, sehingga tertanam sikap ilmiah peserta didik yaitu sikap ingin tahu dan mendorong mencari jawaban atas masalah yang dihadapi. Salah satu upaya agar peserta didik mampu menghadapi masalah dan memecahkannya adalah dengan menggunakan teknologi. Dukungan teknologi seperti teknologi informasi dan komunikasi (TIK) dalam pembelajaran dapat berupa komputer, jaringan internet dan peralatan pendukung lainnya (Munir, 2009).

Hasil penelitin ini juga diperoleh informasi bahwa siswa ulet menghadapi kesulitan belajar kimia meskipun fasilitas TIK di sekolah belum memadai, ulet menghadapi kesulitan belajar kimia yang dimaksud dalam penelitian ini ialah ketika siswa mengalami kesulitan dalam belajar kimia siswa bertanya kepada guru atau teman serta memanfaatkan teknologi informasi dan komunikasi sementara kesiapan TIK di sekolah belum memadai, ini berarti bahwa ada faktor lain yang mendukung siswa menghadapi kesulitan belajar kimia melalui pemanfaatan TIK, faktor yang lain yang diduga mendukung siswa dalam menghadapi kesulitan belajar kimia adalah dukungan dari orang tua. Hal ini diperkuat oleh penelitian yang dilakukan oleh Aisah (2018) mengatakan bahwa sebanyak $77,94 \%$ orang tua siswa menyediakan fasilitas belajar untuk mengakses internet sehingga memudahkan siswa dalam belajar kimia.

Berdasarkan uraian tersebut diketahui bahwa kesiapan TIK memiliki hubungan dengan motivasi belajar kimia siswa. Nilai korelasi yang diperoleh sebesar 0,41. Berdasarkan interpretasi koefisien korelasi dalam Sugiyono (2017) maka hubungan antara kesiapan TIK dengan motivasi belajar kimia siswa berada pada kategori sedang. Adapun penelitian yang dilakukan oleh Zabir (2018) mengatakan bahwa hubungan antara penggunaan teknologi dalam pembelajaran dengan motivasi belajar adalah positif dan signifikan dengan tingkat hubungan yang sedang.

\section{KESIMPULAN}

Kesiapan teknologi informasi dan komunikasi (TIK) dan motivasi belajar kimia siswa kelas XI IPA SMA Negeri 4 Mataram dan SMAN 7 Mataram berada pada kategori sedang. Terdapat hubungan yang positif dan signifikan antara kesiapan teknologi informasi dan komunikasi (TIK) dengan motivasi belajar kimia siswa kelas XI IPA SMA Negeri di Mataram tahun ajaran 2019/2020.

\section{DAFTAR PUSTAKA}

Aisah, S., Kurniasih, D., Fitriani. 2018. Analisis Kemandirian Belajar Siswa pada Mata Pelajaran Kimia di Kelas X SMA Negeri 3 Sintang. Ar-Razi Jurnal Ilmiah. 6(2). 76-86.

Agrahari, A., Singh, S. 2013. The Impact of Information and Communication Technology (ICT) on Achievement of Students in Chemistry at Secondary Level of CBSE and UP Board in India. International Journal of Science and Research. 2(8). 126-129.

Arikunto, S. 2016. Prosedur Penelitian Suatu Pendekatan Praktik. Jakarta: Rineka Cipta.

Fitriani, F., Loka, I. N., Junaidi, E., \& AlIdrus, S. W. (2019). Studi Komparasi Pengaruh Antara Model Pembelajaran Problem Based Learning (PBL) dan Self Regulated Learning (SRL) Terhadap Hasil Belajar Kimia. Chemistry Education Practice, 2(1), 611.

Hasibuan, M.P. dan Ratih, P.S. 2018. Penerapan Kompetensi Kimia SMA Menggunakan Pendekatan Inkuiri Ilmiah pada Mahasiswa S1 Pendidikan Kimia. Jurnal Pendidikan Kimia dan Ilmu Kimia. 1(2). 20-31.

Hamdi, A.S. 2014. Metode Penelitian Kuantitatif Aplikasi dalam Pendidikan. Yogyakarta: CV Budi Utama. 


\section{Chemistry Education Practice, 2 (2), 2019 - 55}

Megawati, Andayani, Junaidi

Mazana, M.Y. 2019. Information and Communication Technology in Mathematics Education-Integration Readiness in Tanzania Higher Education Institutions. IFIP AICT. (552). 409-420.

Musbhirah, Q. U., Muntari, M., \& Al Idrus, S. W. (2018). Pengaruh Model Pembelajaran Joyful Learning dengan Media Kartu Aksi Terhadap Hasil Belajar Kimia. Chemistry Education Practice, 1(1), 26-33.

Mukhtar, R. 2015. Hubungan Motivasi Belajar dengan Hasil Belajar pada Materi Pelajaran Seni Budaya Bidang Seni Musik Siswa Kelas X SMA Piri 1 Yogyakarta. Skripsi.

Munir. 2009. Kurikulum Berbasis Teknologi Informasi dan Komunikasi. Bandung: Alfabeta, CV.
Oktavia, N. 2015. Sistematika Penulisan Karya Ilmiah. Yogyakarta: CV Budi Utama.

Putra, R.S., Nanik, W., dan F. Widhi, M. 2017. Pengaruh Penggunaan Media Pembelajaran Berbasis Aplikasi Android Terhadap Hasil Belajar Siswa. Jurnal Inovasi Pendidikan Kimia. 11(2). 20092018.

Sari, M.L. 2018. Metodologi Penelitian. Yogyakarta: CV Budi Utama.

Setiawan, M.A. 2017. Belajar dan Pembelajaran. Ponorogo: Uwais Inspirasi Indonesia Redaksi.

Sugiyono. 2017. Statistika untuk Penelitian. Bandung: Alfabeta.

Zabir, A. 2018. Pengaruh Pemanfaatan Teknologi Pembelajaran terhadap Motivasi Belajar Siswa SMPN 1 Lanrisang Kabupaten Pinrang. Jurnal Azhari. 1(1). 1-10. 